Tropical Journal of Pharmaceutical Research September 2016; 15 (9): 1967-1972

ISSN: $1596-5996$ (print); 1596-9827 (electronic)

(C) Pharmacotherapy Group, Faculty of Pharmacy, University of Benin, Benin City, 300001 Nigeria.

All rights reserved.

Available online at http://www.tjpr.org

Original Research Article

http://dx.doi.org/10.4314/tjpr.v15i9.22

\title{
Reliability of graphite furnace atomic absorption spectrometry as alternative method for trace analysis of arsenic in natural medicinal products
}

\author{
Reem Saadi Khalid ${ }^{1 *}$, ABM Helaluddin ${ }^{1}$, Reem Saadi Khalid ${ }^{1}$, Mohamed \\ Alaama ${ }^{1}$, Abdualrahman M Abdualkader ${ }^{1}$, Abdulrazak Kasmuri ${ }^{2}$ and Syed Atif \\ Abbas $^{3}$ \\ ${ }^{1}$ Analytical and Bio-Analytical Research Laboratory, Department of Pharmaceutical Chemistry, Faculty of Pharmacy, \\ International Islamic University Malaysia (IIUM), Jalan Istana, Bandar Indera Mahkota, ${ }^{2}$ Department of Basic Medical Science, \\ Faculty of Pharmacy, International Islamic University Malaysia (IIUM), 25200 Kuantan, Pahang, Malaysia, ${ }^{3}$ School of \\ Pharmacy, Taylors University, 1 Jalan Taylor's, 47500 Subang Jaya, Selangor Darul Ehsan, Malaysia
}

*For correspondence: Email: mohdhelal@hotmail.com, abmhelal@iium.edu.my

\begin{abstract}
Purpose: To evaluate the comparative efficiency of graphite furnace atomic absorption spectrometry (GFAAS) and hydride generation atomic absorption spectrometry (HGAAS) for trace analysis of arsenic (As) in natural herbal products (NHPs).

Method: Arsenic analysis in natural herbal products and standard reference material was conducted using atomic absorption spectrometry (AAS), namely, hydride generation ASSAAS (HGAAS) and graphite furnace (GFAAS). The samples were digested with $\mathrm{HNO}_{3}-\mathrm{H}_{2} \mathrm{O}_{2}$ in a ratio of 4:1 using microwave-assisted acid digestion. The methods were validated with the aid of the standard reference material 1515 Apple Leaves (SRM) from NIST

Results: Mean recovery of three different samples of NHPs, using HGAAS and GFAAS, ranged from 89.3 - $91.4 \%$, and 91.7 - $93.0 \%$, respectively. The difference between the two methods was insignificant. $A(P=0.5), B(P=0.4)$ and $C(P=0.88)$ Relative standard deviation (RSD)

RSD, i.e., precision was $2.5-6.5 \%$ and $2.3-6.7 \%$ using HGAAS and GFAAS techniques, respectively. Recovery of arsenic in SRM was 98 and $102 \%$ by GFAAS and HGAAS, respectively.

Conclusion: GFAAS demonstrates acceptable levels of precision and accuracy. Both techniques possess comparable accuracy and repeatability. Thus, the two methods are recommended as an alternative approach for trace analysis of arsenic in natural herbal products.
\end{abstract}

Keywords: Arsenic, Graphite furnace atomic absorption spectrometer (GFAAS), Hydride generation atomic absorption spectrometer (HGAAS), Natural herbal products

Tropical Journal of Pharmaceutical Research is indexed by Science Citation Index (SciSearch), Scopus, International Pharmaceutical Abstract, Chemical Abstracts, Embase, Index Copernicus, EBSCO, African Index Medicus, JournalSeek, Journal Citation Reports/Science Edition, Directory of Open Access Journals (DOAJ), African Journal Online, Bioline International, Open-J-Gate and Pharmacy Abstracts

\section{INTRODUCTION}

Arsenic (As) is a hazardous element that occurs in trace amounts in various environmental samples due to both natural causes and anthropogenic activities [1]. Arsenic shows both metal and non-metal characteristics and has therefore been classified as a metalloid. Within the environment, arsenic exists in organic and inorganic forms in different oxidation states. Among them, arsenite trivalent $\left[\mathrm{As}^{3+}\right]$ has a higher potential of toxicity than the arsenate pentavalent $\left[\mathrm{As}^{5+}\right][2]$. 
Natural herbal products (NHPs) used for medical purposes are of great importance worldwide [3].The safety of NHPs is a vital issue for insuring public health. Arsenic contamination in NHPs has been reported globally [4-6]. Such contamination either originates from the raw materials themselves or released during the manufacturing process [7]. Consumption of contaminated products is encountering serious health risks. Symptoms of acute exposure to As include nausea, gastrointestinal distress and diarrhoea. Long term exposure to arsenic is a matter of concern mostly due its carcinogenic effects. Inorganic arsenic is known as a human carcinogen. Arsenic compounds can promote tumors in various organs such as liver, prostate, kidney [8]. Regular monitoring of such contaminant in NHPs requires simple and accurate analytical method.

Atomic absorption spectroscopy has been widely used for elemental determination at trace concentration levels [9]. Hydride generationatomic absorption spectroscopy (HG-AAS) is routinely used for the determination of As at trace concentration levels in various matrices [10]. However, this method consumes relatively large quantity of chemicals and requires several steps for standards and samples preparation each step has significant impact on the accuracy and precision of the results [11]. Graphite furnace (GFAAS) has been efficiently applied for metals measurements at low concentration levels after reducing the interference problems by various techniques [12]. Therefore, this study aims to evaluate the extent of reliability of GFAAS as an alternative detection method to HG-AAS for As analysis in natural herbal medicinal products by comparing the level accuracy and precision between HGAAS and GFAAS.

\section{EXPERIMENTAL}

\section{Instrumentation}

Perkin Elmer Atomic Absorption Spectrometer (AAS) A Analyst 800 equipped with EDL arsenic lamp. Autosampler graphite furnace (GFAAS) equipped with Zeeman effect background correction. Hydride generation (HGAAS) technique based on the reaction of acidified aqueous samples with a reducing agent to generate volatile hydrides that transport to the quartz cell atomizer by means of argon carrier gas. Table 1 shows the instrumental parameters of GFAAS and HGAAS for As analysis.
Perkin Elmer Titan MPS 16 position vessels digestion system (microwave heating program) was used for samples digestion. Operating temperature from ambient to $170{ }^{\circ} \mathrm{C}$ and recommended pressure of 40 bars.

Table 1: Instrumental parameters of GF-HGAAS used for As analysis

\begin{tabular}{lcc} 
Instrumental parameter & GFAAS & HGAAS \\
\hline Wavelength $(\mathrm{nm})$ & 193.7 & 193.7 \\
Slit $(\mathrm{nm})$ & 0.7 & 0.7 \\
Lamp type & $\mathrm{EDL}$ & EDL \\
Pyrolysis temp/Atomization & $1200 / 2000$ & 900 \\
temp. $\left({ }^{\circ} \mathrm{C}\right)$ & & \\
\hline
\end{tabular}

\section{Chemical reagents and glassware}

All chemicals and reagents used in this study were of analytical and trace metal grades. Trace metal grades $65 \% \mathrm{HNO}_{3}$ and $30 \%$ hydrogen peroxide $\left(\mathrm{H}_{2} \mathrm{O}_{2}\right)$ were obtained from Fisher Malaysia. Stock standard solution of inorganic arsenic (As) with a concentration of $1000 \mathrm{ppm}$, matrix modifiers palladium nitrate $\left(\mathrm{Pd}\left(\mathrm{NO}_{3}\right)_{2}\right)$ and magnesium nitrate $\left(\mathrm{Mg} \quad\left(\mathrm{NO}_{3}\right)_{2}\right)$ were supplied by Perkin Elmer USA. Deionized water was used throughout the study. Sodium borohydride $\left(\mathrm{NaBH}_{4}\right)$, sodium hydroxide $(\mathrm{NaOH})$, L-ascorbic acid $\left(\mathrm{C}_{6} \mathrm{H}_{8} \mathrm{O}_{6}\right)$, and potassium iodide $(\mathrm{KI})$ were obtained from Merck (Germany). A standard reference material (SRM) 1515 apple leaves was obtained from the National Institute of Standards and Technology (NIST, USA). All glassware were soaked in $5 \%(\mathrm{v} / \mathrm{v}) \mathrm{HNO}_{3}$ overnight then rinsed with deionized water and dried using lab dryer FDD 720 prior to use.

\section{Sample preparation}

Natural herbal products originated from specific medicinal plants Eurycoma longifolia Tongkat Ali and Labisia pumila Kacip Fatimah in capsule dosage form were purchased from herbal medicine stores from various regions of Peninsular Malaysia.

An amount $(0.5 \mathrm{~g})$ of each sample was accurately weighed and placed in $75 \mathrm{ml}$ vessel and then $5 \mathrm{ml}$ of acid mixture of $\mathrm{HNO}_{3}: \mathrm{H}_{2} \mathrm{O}_{2}$ in a ratio of $4: 1$ was added. Samples were spiked with known concentration of As standard solution prior to digestion. The vessels were covered and heated to the target temperature of $170{ }^{\circ} \mathrm{C}$ for 10 - 15 min time was required for the digestion. The vessels were removed from the microwave rotor and allowed to cool to room temperature then cautiously opened in a fume hood and the inner walls were rinsed with DI water. The final volume of each sample was made up to $50 \mathrm{~mL}$ with $\mathrm{DI}$ water [13]. In HGAAS analytical technique 
samples were pre-reduced from arsenate pentavalent (V) to arsenite trivalent (III) state by adding $5 \% \mathrm{w} / \mathrm{v} \mathrm{KI}, 5 \% \mathrm{w} / \mathrm{v}$ ascorbic acid and 10 $\% \mathrm{HCl}$, and the treated samples were allowed to stand at room temperature for approximately 40 min prior to analysis.

Spike recovery (R) was computed as In Eq 1.

$R(\%)=\{(\mathrm{Co}-\mathrm{Cr}) / \mathrm{Ca}\} 100$

Where $\mathrm{Co}, \mathrm{Cr}$ and $\mathrm{Cr}$ are the concentration obtained, original concentration and analyte concentration, respectively.

Relative standard deviation was determined as the ratio standard deviation to the mean, expressed as a percentage, while recovery of SRM was calculated as the ratio of the measured concentration (HGAAS or GFAAS) to the certified value, expressed as a percentage

\section{Statistical analysis}

The data are expressed as mean \pm standard deviation (SD, $\mathrm{n}=6)$ ) were evaluated by independent sample t-test using Statistical Package for the Social Sciences (SPSS). $P<$ 0.05 was set as the level of significance.

\section{RESULTS}

\section{Methods comparison and validation}

In this work basic analytical parameters were measured for GFAAS and HGAAS methods for arsenic analysis such as linear range, coefficients of correlation, LOD and LOQ. Calibration curves were constructed for each method in accordance with sensitivity check or the characteristic mass values recommended by the manufacturer. The LOD value was first calculated based on three times standard deviation (SD) for 10 replicates of the blank then the standard deviation of seven replicates of reagent blank spiked with known concentration of As standard solution was multiplied by the Student's t-value to get the LOD value for As while $L O Q$ value was calculated multiplying LOD by 10 [14]. The calibration ranges for HGAAS and GFAAS were 2 - 10 ppb. The coefficients of correlation for HGAAS and GFAAS techniques were 0.998 and 0.999 respectively. The LOD for HGAAS and GFAAS were 0.11 and $0.12 \mathrm{ppb}$ while the LOQ were 1.1 and 1.2 ppb respectively. Accuracy and precision of HGAAS and GFAAS were compared by spike and recovery experiments using three different real samples of NHPs namely A, B and C to evaluate the sample matrix effect on the analytical systems. Samples were spiked with known concentration (7 ppb) of arsenic standard solution prior to microwave assisted acid digestion. The spike samples were analysed by HGAAS and GFAAS to measure the concentration of As analyte recovered as well as the level of the precision by measuring the SD and/or RSD.

The data (mean of six replicates $\pm S D$ ) were analyzed using independent samples t-test to compare the recovery values of arsenic obtained from HGAAS and GFAAS. Figure 1 shows that there is no significant difference between two techniques.

The accuracy of analytical techniques was confirmed by the analysis of standard reference material 1515 apple leaves (SRM) from NIST. Table 3 shows the result of SRM percentage recovery of As analysed by HGAAS and HGAAS.

Table 2: Recovery and RSD (\%) of NHPs samples spiked with (7ppb) of arsenic standard measured with HGAAS and GFAAS

\begin{tabular}{lccc}
\hline Sample & $\begin{array}{c}\text { Recovered concentration in } \\
\text { spiked (ppb) } \pm \text { SD }\end{array}$ & Recovery (\%) & RSD (\%) \\
\hline A & $6.25( \pm 0.31)^{\mathbf{a}}-6.37( \pm 0.43)^{\mathbf{b}}$ & $89.3^{\mathbf{a}}-91^{\mathrm{b}}$ & $4.8^{\mathbf{a}}-6.7^{\mathbf{b}}$ \\
$\mathrm{B}$ & $6.39( \pm 0.13)^{\mathbf{a}}-6.54( \pm 0.31)^{\mathrm{b}}$ & $91.4^{\mathrm{a}}-93^{\mathrm{b}}$ & $2.5^{\mathrm{a}}-4.8^{\mathbf{b}}$ \\
$\mathrm{C}$ & $6.37( \pm 0.4)^{\mathbf{a}}-6.34( \pm 0.14)^{\mathrm{b}}$ & $91.1^{\mathrm{a}}-90^{\mathrm{b}}$ & $6.5^{\mathrm{a}}-2.3^{\mathbf{b}}$ \\
\hline
\end{tabular}

Table 3: Recovery (\%) of SRM for As analysed by HGAAS and GFAAS

\begin{tabular}{lccc}
\hline Sample & Certified value $(\mathbf{p p m})$ & Measured value $(\mathbf{p p m})$ & Recovery (\%) \\
\hline SRM $^{\mathrm{a}}$ & $0.038( \pm 0.007)$ & $0.039( \pm 0.0002)^{\mathrm{a}}$ & 102 \\
$\mathrm{SRM}^{\mathrm{b}}$ & $0038( \pm 0.007)$ & $0.037( \pm 0.0008)$ & 97 \\
\hline${ }^{\mathrm{a}}$ Results from HGAAS; $^{\mathrm{b}}$ results obtained from GFAAS &
\end{tabular}




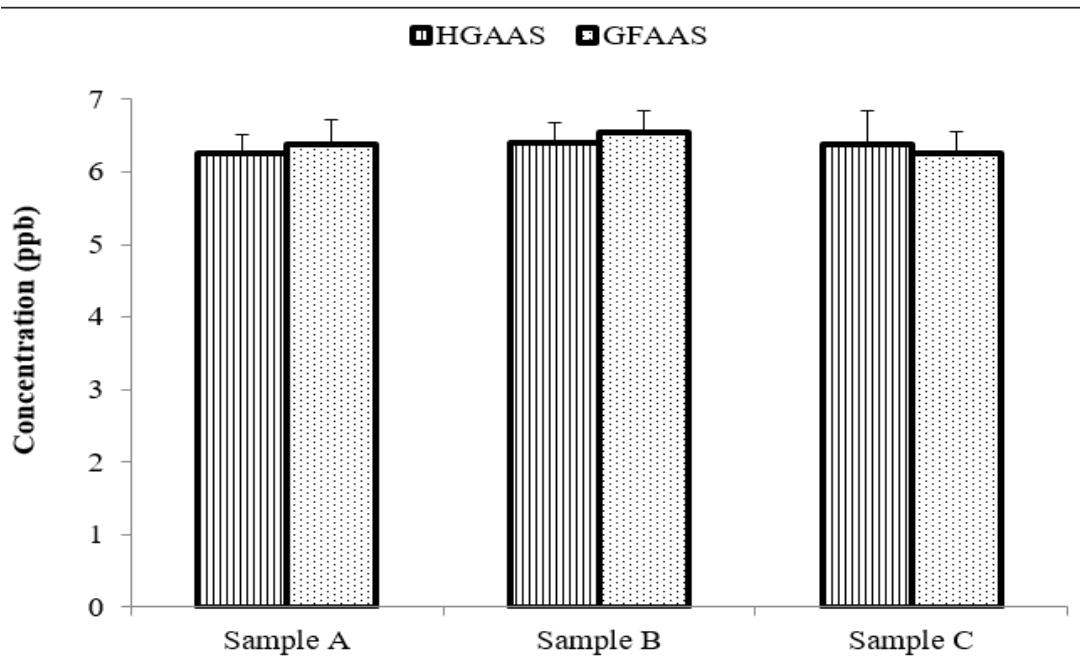

Figure 1: Comparison of HGAAS and GFAAS for the determination of arsenic in three spike samples of NHPs

\section{DISCUSSION}

Generally, arsenic occurs at trace concentration levels in various environmental samples including NHPs $[4,16]$. The complex matrix of NHPs and low contraction level of As in such matrix require adequate analytical method to achieve good quality of analytical data. HGAAS is an accurate robust atomization technique for measuring hydride forming elements at low concentration level. It possesses the advantages of high sensitivity and high tolerance to interferences due to total separation of the analyte as a hydride from the matrix during the atomization stage. However, HGAAS is prone to drawbacks, as it requires tedious procedure for standards and samples preparations and involves hazardous materials. Various technical factors may also influence the hydride forming and the subsequent analytical results, such as tubing condition, valence state of the analyte, quartz cell position, and temperature [11]. GFAAS technique had a substantial improvement in analytical sensitivity after the introduction of matrix modifiers Pd-Mg salts. GFAAS has good detection limits for a majority of elements, with a small sample size for analysis $20 \mu \mathrm{l}$ and minimum requirements for sample preparation [17].

The data for both methods demonstrated good linearity, similar linear ranges relevant to the low level of arsenic concentration in NHPs, and convergent values for $L O D$ and $L O Q$ values. This indicates good sensitivity at trace level of As analysis using HGAAS and HGAAS.

Results obtained from comparison experiments comparing both analytical techniques using spike matrices techniques for three different samples of NHPs as presented in table 2 show convergent recovery values of As in NHPs samples, namely $A, B$, and $C$, as measured by both techniques. Arsenic concentrations were compared by independent samples paired t-test using SPSS for each sample. No significant difference was observed between the methods. Nevertheless, GFAAS yielded higher recovery for As in samples $A$ and $B$, which may be due to the effect of modifiers during the pyrolysis stage by reducing analyte loss and subsequently enhancing the sensitivity of the method. The precision of HGAAS and GFAAS was was within the acceptable values for repeatability of trace analysis [15]. Analysis of 1515 apple leaves (SRM) from NIST using HGAAS and GFAAS techniques confirmed the accuracy of both techniques.

The above results indicate that GFAAS and HGAAS methods possess comparable levels of accuracy and precision. The main advantage of GFAAS technique is the ability to conduct direct analysis with fewer sample pre-treatment requirements.

GFAAS technique has been developed for arsenic analysis in various samples of edible oil. Excellent recovery values were obtained for spike samples of different types of edible oil samples [18]. Emilene and co-authors developed HG-GFAAS detection method for arsenic determination in gasoline samples [19]. In a comparison study between GFAAS and HGAAS for arsenic analysis in different tissues (leg, breast, liver, and heart) of broiler chicken samples, the authors reported a lower detection limit for GFAAS, and adequate level of precision and accuracy in certified reference material and broiler chicken samples compared to HGAAS 
[20]. Results of the relevant studies have indicated that GFAAS offers sufficient levels of accuracy and precision, which is in agreement with the present study findings.

\section{CONCLUSION}

Both techniques demonstrate high levels of accuracy and precision for As trace analysis in NHPs. Natural products of therapeutic interest are being consumed increasingly worldwide. Thus, the developed GFAAS technique is a suitable, simple and less hazardous instrumental analytical method for regular monitoring of As to ensure the safety of NHPs and minimize toxicity.

\section{DECLARATIONS}

\section{Acknowledgement}

The authors would like to express their gratitude to all academic and technical staff of Department of Pharmaceutical Chemistry, Faculty of Pharmacy, IIUM, for their support, as well as to Research Management Centre (RMC), IIUM and Ministry of Higher Education (MOHE), Malaysia for funding this study.

\section{Conflict of Interest}

No conflict of interest associated with this work.

\section{Contribution of Authors}

The authors declare that this work was done by the authors named in this article and all liabilities pertaining to claims relating to the content of this article will be borne by them.

\section{REFERENCES}

1. Jomova K, Jenisova Z, Feszterova M, Baros S, Liska J, Hudecova $D$, Valko $M$. Arsenic toxicity oxidative stress and human disease. J. Appl. Toxicol 2011; 31(2): 95107.

2. Narayana B, Cherian $T$, Mathew M, Paha C. Specetrophotometric detection of arsenic in environmental and biological samples. IJCT 2006; 13:36-40.

3. Nkeiruka IZ, Ebere OO, Obianime AW. Nigerian herbal remedies and heavy metals violation of standard recommended guidelines. Asian Pac J Trop Biomed 2012; 2(3): 1423-1430.

4. Naithani V, Pathak N, Chaudhary M. Estimation of arsenic and mercury in a polyherbal formulation Septiloc. Int. J. Pharm. Sci. Drug Res 2010; 2(1): 78-79.

5. Harriet $O$, Barbara N, Keleabetswe M, Raletamo, Kerstin AM. Determination of potentially toxic heavy metals in traditionally used medicinal plants for HIVIAIDS opportunistic infections in Ngamiland District in Northern Botswana. Anal. Chim. Acta 2012; 730: 42- 48.

6. Adepoju B A, Issa O, Oguntibeju O, Ayoola G, Adejumo O. Analysis of some selected toxic metals in registered herbal products manufactured in Nigeria. Afr. J. Biotechnol 2012; 11(26): 6918-6922.

7. Chan K. Some aspects of toxic contaminants in herbal medicines. Chemosphere, 2003; 52(9): 1361-1371.

8. Klassen CD. Casarette and Doull's Toxicology: the basic science of poisons. 7th ed. USA: Mc Graw Hill; 2008; pp 936-939.

9. Giacomino $A$, Abollino $O$, Malandrino $M$, Karthik $M$, Murugesan $V$. Determination and assessment of the contents of essential and potentially toxic elements in Ayurvedic medicine formulations by inductively coupled plasma-optical emission spectrometry. Microchem. J, (2011); 99(1): 2-6.

10. Gupta S, Pandotra P, Gupta AP, Dhar JK, Sharma G, Ram G, Bedi YS. Volatile (As and $\mathrm{Hg}$ ) and non-volatile $(P b$ and $\mathrm{Cd}$ ) toxic heavy metals analysis in rhizome of Zingiber officinale collected from different locations of North Western Himalayas by atomic absorption spectroscopy. Food Chem Toxicol 2010; 48(10):29662971.

11. Viorica A, Elena C, Luminita V, Mihai S. Determination of mercury in pharmaceuticals by graphite furnace atomic absorption spectrometry with chemical modifier. Acta Chim Slov. 2004; 51:361-372.

12. Sardans J, Montes F, Peñuelas J. Determination of As, $\mathrm{Cd}, \mathrm{Cu}, \mathrm{Hg}$ and $\mathrm{Pb}$ in biological samples by modern electrothermal atomic absorption spectrometry. Spectrochim Acta B Atomic Spectroscopy. 2010; 65(2): 97-112.

13. Zanariah CWN, Mohd AY. Optimisation of digestion method for determination of arsenic in shrimp paste sample using atomic absorption spectrometry. Food Chem 2012; 134: 2406-2410.

14. Ripp J. Analytical detection limit guidance \& laboratory guide for determining method detection limits. Wisconsin Department of Natural Resources. PUBL-TS056-96 Laboratory Certification Program; 1996; $p 24$.

15. AOAC Guidelines for Single-Laboratory Validation of Chemical Methods for Dietary Supplements and Botanicals. Retrieved July 2th, 2011. http://www.aoac.org/dietsupp6/Dietary-Supplementweb-site/ slv_guidelines.pdf

16. Uddin ABM, Khalid RS, Khan UA, Abbas SA. Determination of arsenic content of available traditional medicines in Malaysia using hydride generation atomic absorption spectrometry. Trop J Pharm Res 2013; 12(6): 1053-1056.

17. Sneddon J. Advances in atomic spectroscopy. $A E$ Amsterdam, Elsevier Science; 2002; p 244.

18. Chen SS, Cheng CC, Chou SS. Determination of arsenic in edible oils by direct graphite furnace atomic absorption spectrometry. J Food Drug Anal 2003; 11(3): 214-219.

Trop J Pharm Res, September 2016; 15(9): 1971 
Khalid et al

19. Emilene $M$, Becker $D, M B$, Boschetti $W$, Vale MGR, Ferreira SL, Welz B. Development of an analytical method for the determination of arsenic in gasoline samples by hydride generation-graphite furnace atomic absorption spectrometry. Spectrochim Acta B Atom Spectros 2012; 71: 102-106.
20. Shah $A Q$, Kazi TG, Arain MB, Jamali MK, Afridi $H I$, Jalbani N, Kandhro GA, Baig, JA, SarfraS RA, Ansari $R$. Comparison of electrothermal and hydride generation atomic absorption spectrometry for the determination of total arsenic in broiler chicken. Food Chem 2009; (113): 1351-1355. 